Polymer Journal, Vol. 39, No. 10, pp. 1065-1070 (2007)

(C)2007 The Society of Polymer Science, Japan

\title{
Synthesis of Sugar-Polysiloxane Hybrids Having Rigid Main-Chains and Formation of their Nano Aggregates
}

\author{
Koutarou BePPU, ${ }^{1}$ Yoshiro KANeKo, ${ }^{1}$ Jun-ichi KAdOKAwa, ${ }^{1, \dagger}$ \\ Hidezo MoRI ${ }^{2}$ and Takehiro NISHIKAWA ${ }^{2}$ \\ ${ }^{1}$ Department of Nano-structured \& Advanced Materials, Graduate School of Science and Engineering, \\ Kagoshima University, 1-21-40 Korimoto, Kagoshima 890-0065, Japan \\ ${ }^{2}$ National Cardiovascular Center Research Institute, 5-7-1, Fujishirodai, Suita 565-8565, Japan
}

(Received March 22, 2007; Accepted July 12, 2007; Published August 28, 2007)

\begin{abstract}
We synthesized sugar-polysiloxane hybrids having rigid main-chains by reaction of sugar-lactones with amine-functionalized polysiloxane (1). Reaction of gluconolactone (2) with $\mathbf{1}$ was performed to obtain polysiloxane (3) having polyol moieties derived from glucose. This material has the regularly controlled higher-ordered structure in solid state such as the hexagonal phase. A hydrophilic sugar-polysiloxane hybrid (5) was prepared by reaction of lactobionolactone (4) with $\mathbf{1}$. Furthermore, an amphiphilic sugar-polysiloxane hybrid (8) was synthesized by introduction of stearoyl groups in addition to sugar groups on the surface of $\mathbf{1}$. The SEM image of the amphiphilic material $\mathbf{8}$ exhibited formation of nano aggregates having the particle diameters of $c a .50 \mathrm{~nm}$ in water.

[doi:10.1295/polymj.PJ2006268]

KEY WORDS Glycopolymer / Sugar-lactone / Polysiloxane / Amphiphilic / Hybrid / Nano Aggregate /
\end{abstract}

There has been a growing interest in sugar portions of the glycoproteins because of exhibiting to bind to carbohydrate-recognition proteins, toxins, viruses, and cells. It has been known that a molecular assembly formed from the sugar-residues in the living system expresses stronger recognition ability than that of a single sugar molecule. This, so-called multivalent or cluster effect, has become a principle in the design of artificial glycoconjugate ligands. Therefore, polymeric materials having such functional sugar-residues, i.e., 'glycopolymer', have widely been investigated because these materials efficiently show the multivalent effect. ${ }^{1}$ So far, a number of such glycopolymers have been synthesized, which are composed of various organic polymer main-chains combined with a variety of sugar side-chains. ${ }^{2-6}$

Inorganic polymers such as polysiloxanes have various of interesting properties, e.g., high oxygen permeability, low toxicity, and biocompatibility, which are advantages as biomaterials. Therefore, sugar-polysiloxane hybrids would be expected to have a significant potential for biological applications. In previous study, synthesis of such sugar-inorganic hybrids, composed of polydimethylsiloxane main-chain has been reported. ${ }^{7-10}$ Since the main-chain has relatively flexible nature, nanostructures of the hybrid materials have not been controlled well.

Based on the above viewpoints, we paid attention to amine-functionalized polysiloxanes ${ }^{11,12}$ for the mainchain of new sugar-polysiloxane hybrids, which were prepared by sol-gel reaction of amine-functionalized organoalkoxysilanes in strong acid aqueous solutions. The materials have rigid structures and construct hexagonal phase in solid state, because their frameworks are Si-O-Si network structures derived from trifunctional organoalkoxysilane. Furthermore, the materials are soluble in water and have reactive amino groups on the surface. Their rigidity, solubility, and reactivity would be advantageous properties to controlling nanostructures and introduction of various functional groups on the surface, in addition to the general characteristics of the inorganic polymers.

In previous communication, we briefly reported simple preparation method for a rigid polysiloxane hybrid (3) having polyol moieties using the aminefunctionalized polysiloxane (1) and gluconolactone (2) (Scheme 1). ${ }^{13}$ Because the sugar lactones like 2 react with the amino groups without protection of the hydroxy groups, they are useful substrates for such the simple procedure to exclude multi-reaction steps. However, 2 was not suitable for preparation of materials containing the sugar substituents, because the ring-opened moieties like the side chain of $\mathbf{3}$ formed from 2 had no any sugar-residues. Therefore, we have been carrying out studies on the synthesis of sugarfunctionalized polysiloxane hybrids using disaccharide-lactone such as lactobionolactone (4), because the existence of sugar-residues can be maintained in spite of opening the lactone ring of $\mathbf{4}$ by the reaction with 1.

${ }^{\dagger}$ To whom correspondence should be addressed (Tel: +81-99-285-7743, Fax: +81-99-285-3253, E-mail: kadokawa@eng.kagoshima-u.ac.jp). 
K. BEPPU et al.

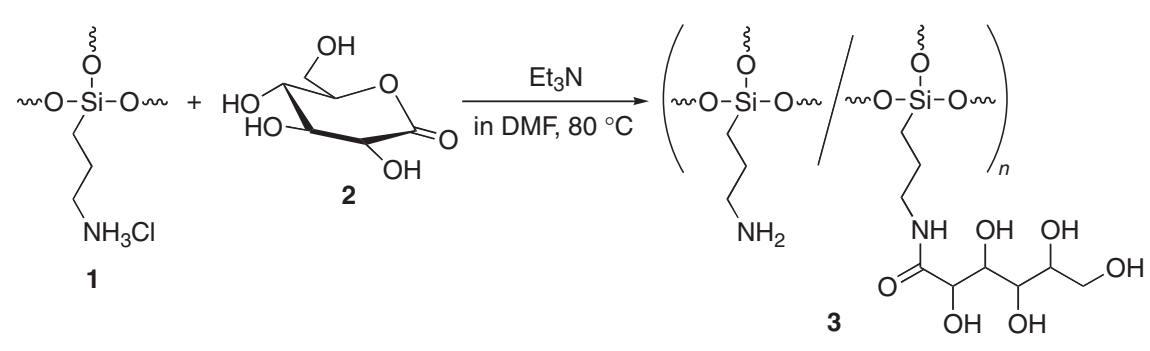

Scheme 1.

In this paper, we describe the synthesis of sugarpolysiloxane hybrids having rigid main-chains by the reaction of sugar-lactones with 1. Furthermore, we prepared an amphiphilic sugar-polysiloxane hybrid by introduction of long alkyl chains in addition to sugar-residues on the surface of $\mathbf{1}$ to promote the formation of the nano aggregates in water, expecting the multivalent effects.

\section{EXPERIMENTAL}

\section{Materials}

The polysiloxane $\mathbf{1}$ was prepared according to the literature procedure. ${ }^{11} \mathrm{~N}, \mathrm{~N}$-Dimethylformamide (DMF), dimethyl sulfoxide (DMSO), and triethylamine were purified by distillation. Other reagents were used as received.

\section{Reaction of 1 with Gluconolactone $2^{13}$}

To a suspension of $1(0.147 \mathrm{~g}, 1.0 \mathrm{mmol}$ unit $)$ in DMF $(2.5 \mathrm{~mL})$ was successively added triethylamine $(0.15 \mathrm{~mL}, 1.1 \mathrm{mmol})$ and a solution of $2(0.891 \mathrm{~g}$, $5.0 \mathrm{mmol})$ in DMF $(10 \mathrm{~mL})$ with vigorously stirring at $80^{\circ} \mathrm{C}$ under argon. After the mixture was stirred further at that temperature for $13 \mathrm{~h}$, the obtained product was isolated by filtration, washed with DMF and acetone, and then dried under reduced pressure at $40^{\circ} \mathrm{C}$ to yield $0.191 \mathrm{~g}$ of the yellow-powdered 3 . ${ }^{1} \mathrm{H}$ NMR $\left(600 \mathrm{MHz}, \mathrm{D}_{2} \mathrm{O}\right): \delta 4.38-4.26(\mathrm{br},-\mathrm{C}(=\mathrm{O})-$ $\mathrm{CH}-), \delta 4.16-4.05(\mathrm{br},-\mathrm{C}(=\mathrm{O}) \mathrm{CH}(\mathrm{OH}) \mathrm{CH}-), \delta 3.88-$ 3.60 (br, $\left.-\mathrm{CH}(\mathrm{OH}) \mathrm{CH}(\mathrm{OH}) \mathrm{CH}_{2}-\right), \delta \quad 3.41-3.10$ and 3.06-2.91 (br, - $\mathrm{NCH}_{2}-$ ), $\delta 1.88-1.45$ (br, $-\mathrm{NCH}_{2} \mathrm{CH}_{2}-$ $\mathrm{CH}_{2} \mathrm{Si}-$ ), $\delta$ 0.94-0.47 (br, $-\mathrm{CH}_{2} \mathrm{Si}-$ ).

\section{Synthesis of Hydrophilic Sugar-Polysiloxane Hybrid} (5)

To a suspension of $1(0.147 \mathrm{~g}, 1.0 \mathrm{mmol}$ unit $)$ in DMSO $(3.0 \mathrm{~mL})$ was successively added triethylamine $(0.34 \mathrm{~mL}, 2.4 \mathrm{mmol})$ and a solution of $4(1.701 \mathrm{~g}, 5.0$ $\mathrm{mmol})$ in DMSO $(10 \mathrm{~mL})$ with vigorously stirring at $80^{\circ} \mathrm{C}$ under argon, and the mixture was stirred further at that temperature for $2 \mathrm{~h}$. The mixture became gradually homogeneous solution. The solution was poured into acetone $(300 \mathrm{~mL})$ to precipitate the powdered product. The precipitated product was isolated by filtration, successively washed with acetone, hydrochloric acid $(\mathrm{HCl})$ methanol solution and methanol, and then dried under reduced pressure at $40{ }^{\circ} \mathrm{C}$ to yield $0.332 \mathrm{~g}$ of the light yellow-powdered $\mathbf{5}$. ${ }^{1} \mathrm{H}$ NMR $\left(600 \mathrm{MHz}, \mathrm{D}_{2} \mathrm{O}\right): \delta$ 4.65-4.50 (br, - $\mathrm{OCH}-$ $(\mathrm{CH}-) \mathrm{O}-), \delta 4.50-4.32$ (br, $-\mathrm{C}(=\mathrm{O}) \mathrm{CH}(\mathrm{OH})-), \delta 4.32-$ 4.13 (br, $-\mathrm{C}(=\mathrm{O}) \mathrm{CH}(\mathrm{OH}) \mathrm{CH}(\mathrm{OH})-), \delta 4.08-3.49$ (br, $-\mathrm{CH}(\mathrm{O}-) \mathrm{CH}(\mathrm{OH}) \mathrm{CH}_{2} \mathrm{OH},-\mathrm{CH}(\mathrm{OH}) \mathrm{CH}(\mathrm{OH}) \mathrm{CH}(\mathrm{OH})-$ $\left.\mathrm{CH}(\mathrm{O}-) \mathrm{CH}_{2} \mathrm{OH}\right), \delta$ 3.40-3.12 (br, $-\mathrm{C}(=\mathrm{O}) \mathrm{NHCH}_{2}-$ ), $\delta$ 3.12-2.87 (br, $\mathrm{Cl} \cdot \mathrm{NH}_{3} \mathrm{CH}_{2}$ ), $\delta$ 1.95-1.43 (br, $-\mathrm{NCH}_{2} \mathrm{CH}_{2} \mathrm{CH}_{2} \mathrm{Si}-$ ), $\delta$ 0.93-0.50 (br, - $\mathrm{CH}_{2} \mathrm{Si}$-).

\section{Synthesis of Stearoyl-Carrying Polysiloxane (7)}

To a solution of $1(0.440 \mathrm{~g}, 3.0 \mathrm{mmol}$ unit $)$ in water $(10 \mathrm{~mL})$ was successively added triethylamine $(1.0 \mathrm{~mL}, 7.2 \mathrm{mmol})$ and a solution of stearoyl chloride (6) $(0.182 \mathrm{~g}, 0.6 \mathrm{mmol})$ in DMF $(30 \mathrm{~mL})$ with vigorously stirring at room temperature, and the solution was stirred further at that temperature for $10 \mathrm{~min}$. After $5 \mathrm{~mol} / \mathrm{L} \mathrm{HCl}$ aqueous solution $(2.88 \mathrm{~mL}, 14.4$ mmol) was added to this mixture and this solution was stirred further for $5 \mathrm{~min}$, the solution was poured into acetone $(300 \mathrm{~mL})$ to precipitate the powdered product. The precipitated product was isolated by filtration, washed with acetone and chloroform, and then dried under reduced pressure at $40^{\circ} \mathrm{C}$ to yield $0.437 \mathrm{~g}$ of the white-powdered 7. ${ }^{1} \mathrm{H} \mathrm{NMR}(600 \mathrm{MHz}$, DMSO- $\left.d_{6}-\mathrm{D}_{2} \mathrm{O}\right): \delta 3.09-2.72\left(\mathrm{br},-\mathrm{NCH}_{2}-\right), \delta 2.20$ 2.01 (br, $-\mathrm{C}(=\mathrm{O}) \mathrm{CH}_{2}-$ ), $\delta$ 1.88-1.55 (br, $-\mathrm{NCH}_{2} \mathrm{CH}_{2}-$ $\left.\mathrm{CH}_{2} \mathrm{Si}-\right), \delta$ 1.50-1.40 (br, $\left.-\mathrm{C}(=\mathrm{O}) \mathrm{CH}_{2} \mathrm{CH}_{2}-\right), \delta 1.28-$ 1.10 (br, $-\mathrm{CCH}_{2} \mathrm{C}$-), $\delta$ 0.95-0.45 (br, $-\mathrm{CH}_{3},-\mathrm{CH}_{2} \mathrm{Si}$-).

Synthesis of Amphiphilic Sugar-Polysiloxane Hybrid (8)

To a solution of $7(0.150 \mathrm{~g}, 1.3 \mathrm{mmol}$ unit $)$ in DMSO $(5 \mathrm{~mL})$ was successively added triethylamine $(0.46 \mathrm{~mL}, 3.3 \mathrm{mmol})$ and a solution of $4(2.212 \mathrm{~g}$, $6.5 \mathrm{mmol})$ in DMSO $(15 \mathrm{~mL})$ with stirring at $80^{\circ} \mathrm{C}$, and the solution was stirred further at that temperature for $2 \mathrm{~h}$. The solution was poured into acetone (300 $\mathrm{mL}$ ) to precipitate the powdered product. The precipitated product was isolated by filtration, successively washed with acetone, $\mathrm{HCl}$ methanol solution and 
methanol, and then dried under reduced pressure at $40{ }^{\circ} \mathrm{C}$ to yield $0.270 \mathrm{~g}$ of the light yellow-powdered 8. ${ }^{1} \mathrm{H}$ NMR (600 MHz, DMSO- $\left.d_{6}-\mathrm{D}_{2} \mathrm{O}\right): \delta 4.46-4.28$ (br, - $\mathrm{OCH}(\mathrm{CH}-) \mathrm{O}-), \delta$ 4.28-4.11 (br, $-\mathrm{C}(=\mathrm{O}) \mathrm{CH}$ $(\mathrm{OH})-), \delta$ 4.11-3.95 (br, $-\mathrm{C}(=\mathrm{O}) \mathrm{CH}(\mathrm{OH}) \mathrm{CH}(\mathrm{OH})-)$, $\delta$ 3.90-3.28 (br, - $\mathrm{CH}(\mathrm{O}-) \mathrm{CH}(\mathrm{OH}) \mathrm{CH}_{2} \mathrm{OH},-\mathrm{CH}(\mathrm{OH})-$ $\mathrm{CH}(\mathrm{OH}) \mathrm{CH}(\mathrm{OH}) \mathrm{CH}(\mathrm{O}-) \mathrm{CH}_{2} \mathrm{OH}$, overlapped with HOD signal), $\delta$ 3.28-2.96 (br, $\left.-\mathrm{C}(=\mathrm{O}) \mathrm{NHCH}_{2}-\right), \delta$ 2.96-2.70 (br, $\mathrm{Cl} \cdot \mathrm{NH}_{3} \mathrm{CH}_{2}-$ ), $\delta 2.20-2.01$ (br, $-\mathrm{C}(=\mathrm{O})$ $\mathrm{CH}_{2}-$ ), $\delta$ 1.80-1.32 (br, - $\mathrm{NCH}_{2} \mathrm{CH}_{2} \mathrm{CH}_{2} \mathrm{Si}$-, $-\mathrm{C}(=\mathrm{O})$ $\mathrm{CH}_{2} \mathrm{CH}_{2}-$ ), $\delta$ 1.28-1.13 (br, $\left.-\mathrm{CCH}_{2} \mathrm{C}-\right), \delta \quad 0.88-0.80$ (br, $-\mathrm{CH}_{3}$ ), $\delta$ 0.80-0.36 (br, - $\mathrm{CH}_{2} \mathrm{Si}$-).

\section{Measurements}

The IR spectra were recorded using a SHIMADZU FT/IR-8400 spectrometer. The ${ }^{1} \mathrm{H}$ NMR spectra $(600 \mathrm{MHz})$ were recorded using a JEOL ECA600 spectrometer. The gel permeation chromatographic (GPC) analyses were performed by using a TOSOH CCPD with RI detector under the following conditions: Shodex GF-310 column with water as the eluent at a flow rate of $0.5 \mathrm{~mL} / \mathrm{min}$. The calibration curve was obtained using pullulan standards. The X-ray diffraction (XRD) measurements were conducted at a scanning speed of $2 \theta=0.2^{\circ} / \mathrm{min}$ using a RINT 1200 (Rigaku Co., Ltd) diffractometer with Ni-filtered $\mathrm{CuK} \alpha$ radiation $(\lambda=0.15418 \mathrm{~nm})$. The scanning electron microscope (SEM) images were obtained using a Hitachi S-4100 electron microscope. The dynamic light scattering (DLS) measurement was performed on a Zetasizer 3000 (Malvern Instruments).

\section{RESULTS AND DISCUSSION}

\section{Reaction of 1 with 2}

As previously reported, ${ }^{13}$ an introduction of $\mathbf{2}$ to $\mathbf{1}$ was performed by heating at $80^{\circ} \mathrm{C}$ in the presence of triethylamine in DMF to prepare a rigid polysiloxane 3 having polyol moieties (Scheme 1). The obtained product 3 was soluble in water and DMSO, but insoluble in typical organic solvents such as methanol, acetone, chloroform, and $n$-hexane.

The IR spectrum of the product showed an absorption at $1150 \mathrm{~cm}^{-1}$ attributed to the $\mathrm{Si}-\mathrm{O}$ bond of the polysiloxane, an absorption at $1080 \mathrm{~cm}^{-1}$ assigned to the $\mathrm{C}-\mathrm{O}$ bond of the polyol moiety derived from 2, and an absorption at $1650 \mathrm{~cm}^{-1}$ due to the $\mathrm{C}=\mathrm{O}$ bond of the amido group. In addition, the ${ }^{1} \mathrm{H}$ NMR spectrum in $\mathrm{D}_{2} \mathrm{O}$ of the product showed both signals due to $\mathbf{1}$ and 2 . Furthermore, a methylene signal ( $\delta$ $3.41-3.10$ ) neighboring the amido group was appeared at lower magnetic field compared with a signal $(\delta$ 3.06-2.91) neighboring the unreacted amino group. These spectroscopic results indicated that the product has the structure $\mathbf{3}$ connecting $\mathbf{1}$ with $\mathbf{2}$ by the covalent bonds. The functionality of $\mathbf{2}$ to $\mathbf{1}$ was calculated to be ca. $75 \%$ based on the integrated ratio of the methylene signal neighboring the amido group to the methylene signal neighboring the silicon atom.

The molecular weights of $\mathbf{3}$ and $\mathbf{1}$ were evaluated by GPC analyses with water as the eluent. The GPC peak of $\mathbf{3}$ was shifted to the range of higher molecular weight compared to that of $\mathbf{1}$. The $M_{\mathrm{n}}$ values of $\mathbf{3}$ and 1 estimated using pullulan standards were 21,200 $\mathrm{g} / \mathrm{mol}\left(M_{\mathrm{w}} / M_{\mathrm{n}}=1.33\right)$ and $10,300 \mathrm{~g} / \mathrm{mol}\left(M_{\mathrm{w}} / M_{\mathrm{n}}=\right.$ 1.41), respectively.

The XRD profile of $\mathbf{3}$ showed three peaks with the $d$-value ratio of $1: 1 / \sqrt{3}: 1 / 2$ assigned to the (100), (110), and (200) peaks, respectively, indicating that the product has a hexagonal phase. Additionally, the $d$-value of the (100) peak of $\mathbf{3}(d=1.76 \mathrm{~nm})$ was larger than that of $\mathbf{1}(d=1.41 \mathrm{~nm})$. This indicates that the hexagonal phase in solid state was maintained in spite of the increase in the $d$-value by introduction of $\mathbf{2}$ to $\mathbf{1}$.

The above analytical data indicated that $\mathbf{2}$ efficiently reacted with the amino groups in $\mathbf{1}$, giving rise to $\mathbf{3}$. To introduce the sugar moieties such as galactose residues on the surface of $\mathbf{1}$ by means of this reaction manner, the following experiments were performed using lactobionolactone 4 .

\section{Synthesis of Hydrophilic Sugar-Polysiloxane Hybrid 5}

We investigated synthesis of galactose-functionalized polysiloxane hybrid $\mathbf{5}$ by the reaction of $\mathbf{4}$ with 1. Procedures for synthesis of $\mathbf{5}$ were almost same as those of $\mathbf{3}$. Since the reaction in DMF gave the insoluble product, however, we employed DMSO as the alternative solvent, which was favorable for this reaction system. When an introduction of $\mathbf{4}$ to $\mathbf{1}$ was performed by heating at $80^{\circ} \mathrm{C}$ in the presence of triethylamine in DMSO (Scheme 2), the initial reaction system was heterogeneous, which gradually became homogeneous with progress of the reaction. After the product was isolated as the fraction insoluble in acetone, unreacted amino groups were converted to ammonium cations by addition of $\mathrm{HCl}$ methanol solution in order to increase solubility and stability of the product in water. The obtained product 5 was soluble in water and DMSO, but insoluble in typical organic solvents such as methanol, acetone, chloroform, and $n$-hexane.

The IR spectrum of the product showed absorptions at $1650 \mathrm{~cm}^{-1}$ attributed to the $\mathrm{C}=\mathrm{O}$ bond of the amido group, indicating the introduction of $\mathbf{4}$ to $\mathbf{1}$. The ${ }^{1} \mathrm{H}$ NMR spectrum in $\mathrm{D}_{2} \mathrm{O}$ of the product in Figure 1 shows both signals derived from 1 and $\mathbf{4}$. Furthermore, a methylene signal $\mathbf{H}_{\mathbf{c}}$ neighboring the amido group appeared at lower magnetic field compared with a signal $\mathbf{H}_{\mathbf{c}^{\prime}}$ neighboring the unreacted amino group. These spectroscopic data support the structure $\mathbf{5}$ of 


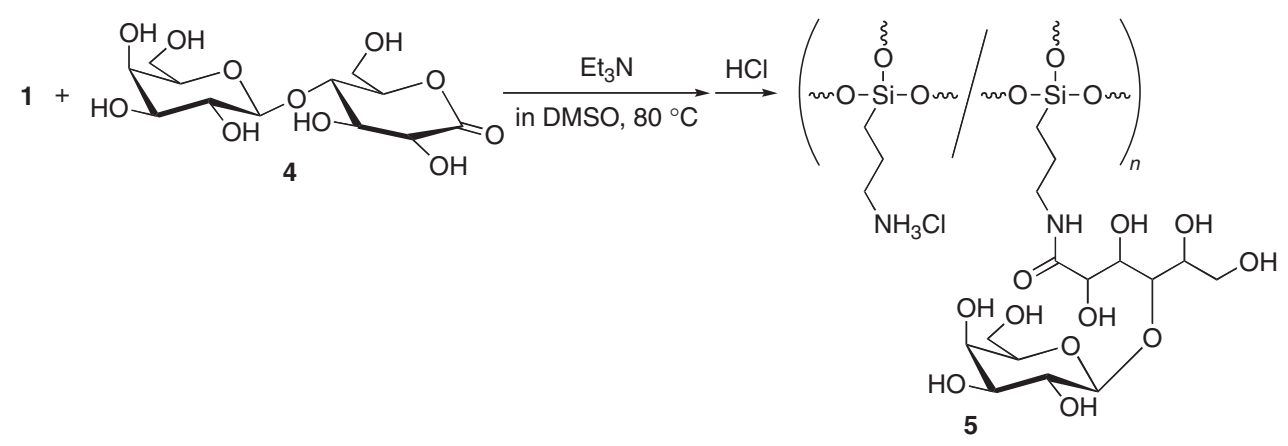

Scheme 2.

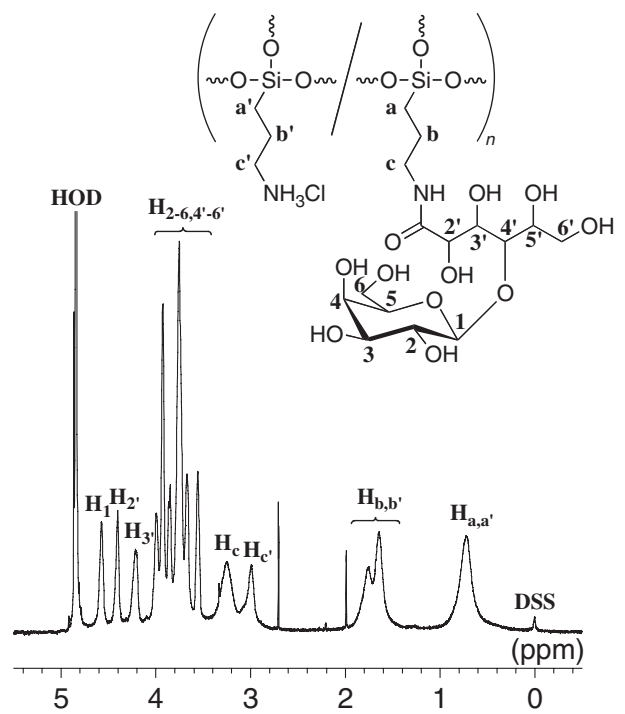

Figure 1. ${ }^{1} \mathrm{H}$ NMR spectrum of 5 in $\mathrm{D}_{2} \mathrm{O}$. Chemical shifts were referenced to sodium 2,2-dimethyl-2-silapentane-5-sulfonate (DSS) ( $\delta 0.0 \mathrm{ppm})$.

the product. The functionality of $\mathbf{4}$ to $\mathbf{1}$ was calculated by the integrated ratio of the signal $\mathbf{H}_{\mathbf{1}}$ to the signals $\mathbf{H}_{\mathbf{a}}$ and $\mathbf{H}_{\mathbf{a}^{\prime}}$ in Figure 1 to be $c a .57 \%$. Although the XRD profile of $\mathbf{3}$ showed three peaks for a typical hexagonal phase as described above, no diffraction peak was observed for $\mathbf{5}$, indicating that a regular higher-ordered structure was not formed in the solid state. This would be because that the bulkiness of $\mathbf{4}$ affected the higher-ordered structure of $\mathbf{5}$. However, $\mathbf{5}$ probably has the rigid structure in the solution due to the Si-O-Si network structure of the main-chain derived from trifunctional organoalkoxysilane. The molecular weight $\left(M_{\mathrm{n}}\right)$ of $\mathbf{5}$ estimated by GPC analysis with water as the eluent using pullulan standards was $44,700 \mathrm{~g} / \mathrm{mol}\left(M_{\mathrm{w}} / M_{\mathrm{n}}=1.44\right)$.

\section{Synthesis of Amphiphilic Sugar-Polysiloxane Hybrid 8}

To promote the formation of the nano aggregates of sugar-polysiloxane hybrid, we attempted synthesis of an amphiphilic hybrid $\mathbf{8}$ by introduction of the hydrophobic stearoyl groups in addition to the hydrophilic sugar groups on the surface of $\mathbf{5}$. However, the reaction of $\mathbf{5}$ with stearoyl chloride $\mathbf{6}$ did not proceed to obtain $\mathbf{8}$, probably due to bulkiness of sugar-residues existed on the surface of $\mathbf{5}$. As an alternative reaction manner, an introduction of $\mathbf{6}$ to $\mathbf{1}$ was firstly carried out in the presence of triethylamine in water/DMF mixed solvent at room temperature to produce stearoyl-carrying polysiloxane 7 (Scheme 3). After addition of $\mathrm{HCl}$ aqueous solution to this reaction solution, the product was isolated as the fraction insoluble in acetone. The obtained product 7 was soluble in DMSO, but insoluble in water.

The IR spectrum of the product showed an absorption at $1640 \mathrm{~cm}^{-1}$ assigned to the $\mathrm{C}=\mathrm{O}$ bond of the amido group. In addition, the ${ }^{1} \mathrm{H}$ NMR spectrum in DMSO- $d_{6}$ (including a small amount of $\mathrm{D}_{2} \mathrm{O}$ ) of the product in Figure 2 shows both signals derived from 1 and 6 . These spectroscopic results indicate the intro-

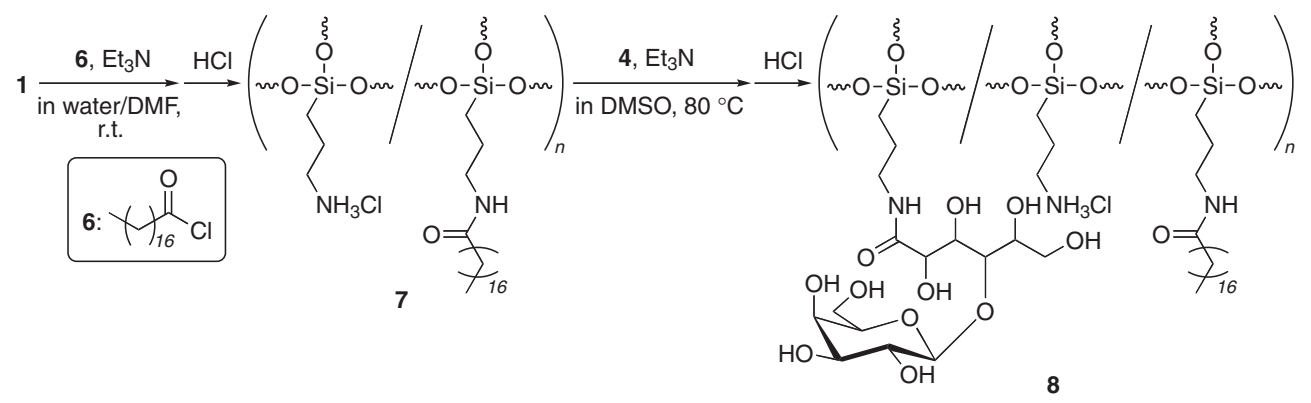

Scheme 3. 


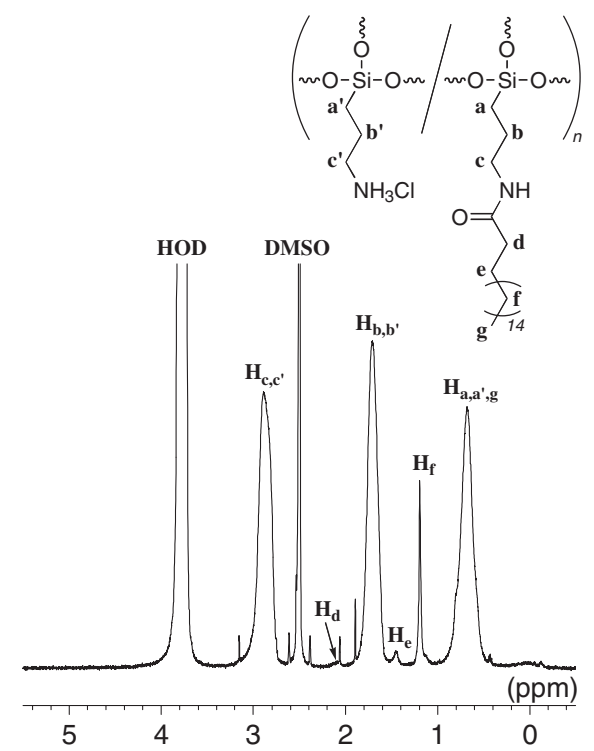

Figure 2. ${ }^{1} \mathrm{H}$ NMR spectrum of 7 in DMSO- $d_{6}$ (including a small amount of $\mathrm{D}_{2} \mathrm{O}$ ). Chemical shifts were referenced to DMSO ( $\delta 2.5 \mathrm{ppm})$.

duction of $\mathbf{6}$ to $\mathbf{1}$, leading to 7 . The functionality of 6 to 1 was calculated to be $c a$. $2 \%$ based on the integrated ratio of the signal $\mathbf{H}_{\mathbf{f}}$ to the signal $\mathbf{H}_{\mathbf{b}}$ and $\mathbf{H}_{\mathbf{b}^{\prime}}$. When the feed ratio of $\mathbf{6}$ to $\mathbf{1}$ was increased, the insoluble product was obtained.

As a second step, we carried out a reaction of $\mathbf{4}$ with 7 by heating at $80^{\circ} \mathrm{C}$ in the presence of triethylamine in DMSO to obtain amphiphilic sugar-polysiloxane hybrid 8 (Scheme 3). The product was isolated as the fraction insoluble in acetone, followed by washing with acetone, $\mathrm{HCl}$ methanol solution, and methanol. The obtained product $\mathbf{8}$ was soluble in water and DMSO, but insoluble in typical organic solvents such as methanol, acetone, chloroform, and $n$-hexane.

The IR spectrum of the product showed an absorption at $1140 \mathrm{~cm}^{-1}$ attributed to the $\mathrm{Si}-\mathrm{O}$ bond, an absorption at $1080 \mathrm{~cm}^{-1}$ assigned to the $\mathrm{C}-\mathrm{O}$ bond of $\mathbf{4}$, and an absorption at $1650 \mathrm{~cm}^{-1}$ due to the $\mathrm{C}=\mathrm{O}$ bond of the amido group. Additionally, the ${ }^{1} \mathrm{H}$ NMR spectrum in DMSO- $d_{6}$ (including a small amount of $\mathrm{D}_{2} \mathrm{O}$ ) of the product in Figure 3a shows signals derived from 1, 4, and $\mathbf{6}$. Furthermore, the methylene signals $\mathbf{H}_{\mathbf{a}}$ and $\mathbf{H}_{\mathbf{b}}$ of the product shift to higher field and the methylene signal $\mathbf{H}_{\mathbf{c}}$ shifts to lower field compared with those of 7 . These shifts have also been observed in the synthesis of $3,{ }^{13}$ and are attributed to progress of the amidation reaction of $\mathbf{7}$ with $\mathbf{4}$. These spectroscopic results fully support the structure of the sugarand stearoyl-functionalized polysiloxane $\mathbf{8}$. The functionality of $\mathbf{4}$ to $\mathbf{1}$ was calculated by the integrated ratio of the signal $\mathbf{H}_{\mathbf{f}^{\prime}}$ to the signal $\mathbf{H}_{\mathbf{1}}$ in Figure 3 to be $c a .48 \%$, when the reaction was carried out under the conditions as described in experimental sec-

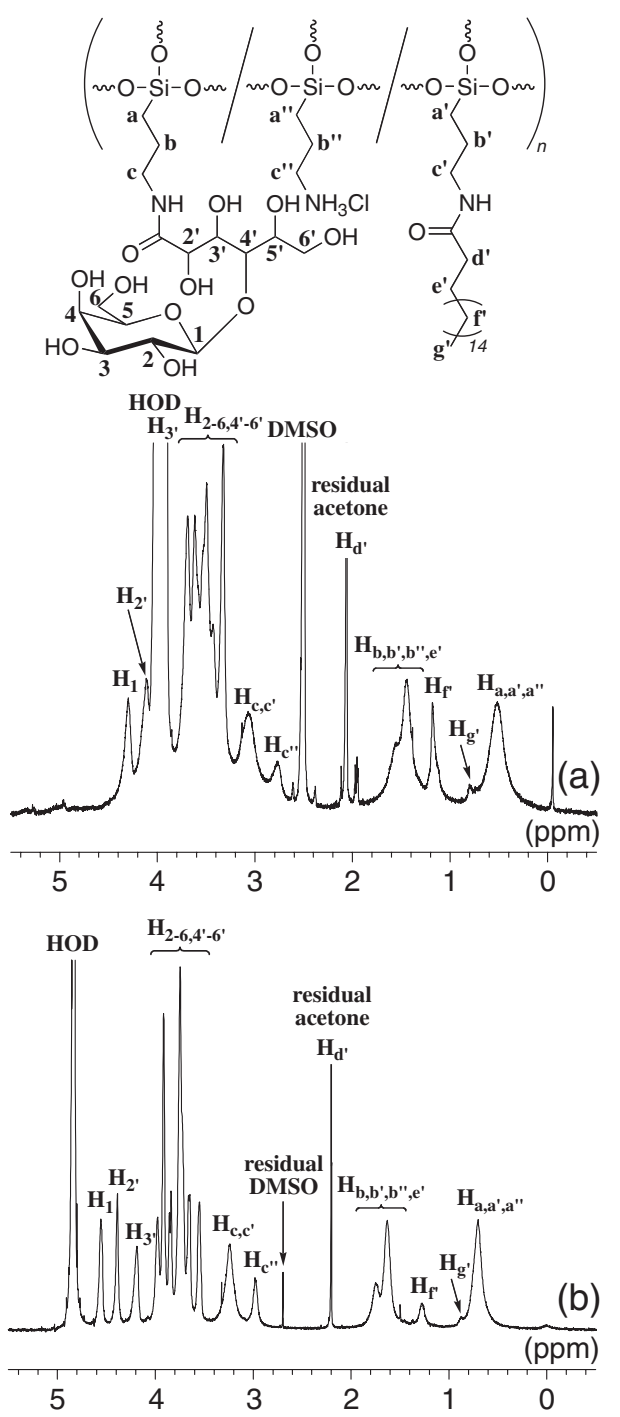

Figure 3. ${ }^{1} \mathrm{H}$ NMR spectrum of 8 (a) in DMSO- $d_{6}$ (including a small amount of $\mathrm{D}_{2} \mathrm{O}$ ) and (b) in $\mathrm{D}_{2} \mathrm{O}$. Chemical shifts were referenced to DMSO ( $\delta 2.5 \mathrm{ppm})$ and DSS ( $\delta 0.0 \mathrm{ppm})$, respectively.

tion. The functionalities were variable by changing the feed ratio of $\mathbf{4}$ to 7 .

Interestingly, intensity of a signal $\mathbf{H}_{\mathbf{f}^{\prime}}$ due to stearo$\mathrm{yl}$ group of $\mathbf{8}$ in $\mathrm{D}_{2} \mathrm{O}$ decreases compared with that in DMSO- $d_{6}$ (Figure $3 \mathrm{~b}$ ). This observation indicates that the stearoyl groups existed in the inside of the intra and intermolecular aggregates of $\mathbf{8}$ in $\mathrm{D}_{2} \mathrm{O}$. To confirm the formation of nano aggregates of $\mathbf{8}$ in water, SEM image of $\mathbf{8}$ was taken. The SEM specimen was prepared by evaporating an aqueous solution of $\mathbf{8}$ on a spinning aluminium plate. The SEM image of the surface of $\mathbf{8}$ coated on the aluminum plate shows that nano aggregates were formed from $\mathbf{8}$ (Figure 4); nano aggregates having the particle diameters of $c a .50 \mathrm{~nm}$ are appearing at high frequency and larger particles that represent a diameter of $c a .500 \mathrm{~nm}$ are coexisting with smaller aggregates at much lower frequency (a few aggregates in a SEM image). The particle size 


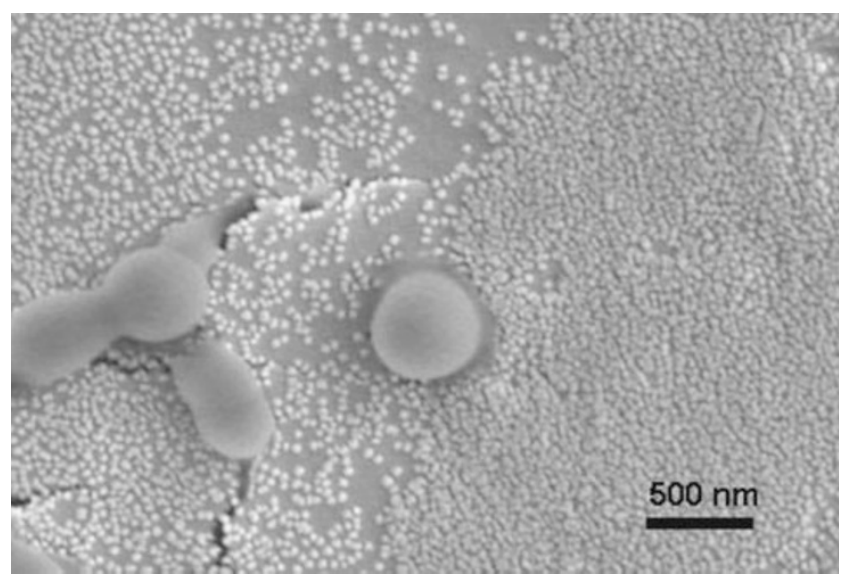

Figure 4. SEM image of 8.

was also confirmed by dynamic light scattering (DLS) measurement. The mean diameter of the particle composed of 8 was $67.7 \pm 4.5 \mathrm{~nm}$ (poly dispersity index: 0.273 ) in water. The aggregate size corresponds well to that was observed in the SEM image of the spincoating sample of $\mathbf{8}$.

\section{CONCLUSIONS}

The amino groups existed on the surface of the rigid polysiloxane (1) efficiently reacted with gluconolactone (2) to give the corresponding hybrid (3). This reaction manner was employed for preparation of the hydrophilic sugar-polysiloxane hybrid (5), which was achieved by the reaction of $\mathbf{1}$ with lactobionolactone (4). Furthermore, the amphiphilic sugar-polysiloxane hybrid (8) was also derived from $\mathbf{1}$ by the successive reactions with stearoyl chloride (6) and with $\mathbf{4}$. The obtained hybrid materials $\mathbf{5}$ and $\mathbf{8}$ have galactose residues on their surfaces. Although hybrid $\mathbf{3}$ had the regular higher-ordered structure in the solid state, hydro- philic sugar-polysiloxane hybrid $\mathbf{5}$ did not form such a structure by the bulkiness of $\mathbf{4}$. However, amphiphilic sugar-polysiloxane hybrid $\mathbf{8}$ formed the nano aggregates in water, which was confirmed by the ${ }^{1} \mathrm{H}$ NMR, SEM, and DLS analyses, expecting the multivalent effects of sugar-residues. The present materials are new class of sugar-inorganic hybrids, which have rigid polysiloxane main-chains.

Acknowledgment. The author (T.N.) thanks Dr. Tetsuji Yamaoka and Dr. Atsushi Mahara of National Cardiovascular Center for dynamic light scattering measurement.

\section{REFERENCES}

1. M. Okada, Prog. Polym. Sci., 26, 67 (2001).

2. K. Kobayashi, A. Tsuchida, T. Usui, and T. Akaike, Macromolecules, 30, 2016 (1997).

3. X. L. Sun, K. M. Faucher, M. Houston, D. Grande, and E. L. Chaikof, J. Am. Chem. Soc., 124, 7258 (2002).

4. Q. Wang, J. S. Dordick, and R. J. Linhardt, Chem. Mater., 14, 3232 (2002).

5. A. B. Lowe, B. S. Sumerlin, and C. L. McCormick, Polymer, 44, 6761 (2003).

6. L. Albertin, M. Stenzel, C. Barner-Kowollik, L. J. R. Foster, and T. P. Davis, Macromolecules, 37, 7530 (2004).

7. G. Jonas and R. Stadler, Acta. Polym., 45, 14 (1994).

8. V. Braunmühl, G. Jonas, and R. Stadler, Macromolecules, 28, 17 (1995).

9. V. Braunmühl and R. Stadler, Polymer, 39, 1617 (1998).

10. K. Loos, G. Jonas, and R. Stadler, Macromol. Chem. Phys., 202, 3210 (2001).

11. Y. Kaneko, N. Iyi, K. Kurashima, T. Matsumoto, T. Fujita, and K. Kitamura, Chem. Mater., 16, 3417 (2004).

12. Y. Kaneko, N. Iyi, T. Matsumoto, and K. Kitamura, Polymer, 46, 1828 (2005).

13. Y. Kaneko, J. Kadokawa, M. Setoguchi, and N. Iyi, Polymer, 46, 8905 (2005). 